\title{
COMPORTAMENTO SUICIDA: UMA REVISÃO INTEGRATIVA DA LITERATURA
}

\author{
SUICIDE BEHAVIOR: AN INTEGRATING LITERATURE REVIEW
}

\author{
Jéssica Vieira de Sousa Silva ${ }^{\mathrm{I}}$ \\ Hinayana Leão Motta ${ }^{\text {II }}$
}

\section{RESUMO}

Este estudo tem como finalidade executar uma revisão integrativa da literatura, utilizando periódicos no recorte temporal de 2000 a 2017, analisar a existência de fatores de risco para o suicídio, verificar quais as formas de intervenção psicoterápicas mais utilizadas e fornecer subsídios compilados para profissionais de saúde. Visto que a metodologia utilizada foi a revisão integrativa da literatura, visando a busca de fontes cientificas publicadas, foram incluídos artigos indexados nas seguintes bases de dados: Biblioteca Virtual de Psicologia - Bvs-Psi, da Scientific Electronic Library Online - Scielo, LILACS (Literatura Latino-Americana e do Caribe em Ciências da Saúde) e Portal de Periódicos Eletrônicos de Psicologia (PePSIC). De acordo com a análise foi possível perceber que em relação aos fatores os que mais se destacam são: diagnóstico psicopatológico, principalmente depressão e comorbidades, uso de substâncias psicoativas, sentimento de tristeza e desesperança, desemprego, ser do sexo masculino, não possuir filhos, possuir idade entre 15 a 44 anos e a partir de 65 anos, assim como a falta de fatores protetivos. Em relação as intervenções psicoterápicas mais utilizadas Terapia Cognitivo-Comportamental destaca-se na literatura, porém, foi verificado por meio dos dados existentes que há uma carência de pesquisas acerca de intervenções psicoterápicas em pacientes com comportamento suicida.

Palavras-chave: Suicídio. Depressão. Fatores de risco. Tentativas de suicídio.

\section{ABSTRACT}

The purpose of this study is to carry out a integrative review of the literature, using periodic data from 2000 to 2017, analyzing the existence of risk factors for suicide, verifying the most used forms of psychotherapeutic intervention and providing subsidies compiled for health professionals. Since the methodology used was the systematic review of the literature, in order to search for published scientific sources, articles indexed in the following databases were included: Virtual Library of Psychology - Bvs-Psi, Scientific Electronic Library Online - Scielo, LILACS Latin American and Caribbean in Health Sciences) and Portal of Electronic Journals of Psychology (PePSIC). According to the analysis, it was possible to perceive that the factors that stand out most are: psychopathological diagnosis, mainly depression and comorbidities, use of psychoactive substances, feelings of sadness and hopelessness, unemployment, being male, having no children, to be aged between 15 and 44 years and from 65 years, as well as the lack of protective factors. Regarding the most used psychotherapeutic interventions Cognitive-Behavioral Therapy is highlighted in the literature, however, it was verified from existing data that there is a lack of research on psychotherapeutic interventions in patients with suicidal behavior.

Keywords: Suicide. Depression. Risk factors. Attempted suicide.

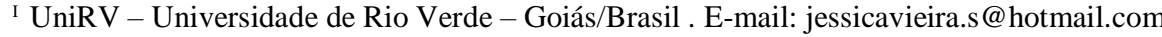

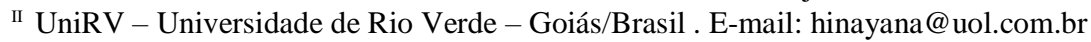




\section{INTRODUÇÃO}

Falar acerca do tema deste trabalho, abordando o suicídio é muito proeminente, nos dias atuais. A cada ano que se passa morre cerca de um milhão de pessoas por suicídio. Estima-se que em 2020 o ato de auto-extermínio chegue a ter uma prevalência de $2.4 \%$ do índice de mortalidade no mundo inteiro. Além disso, o número de tentativas de suicídio é aproximadamente 20 vezes mais alto que o suicídio consumado (FOTTI et al. 2006). Segundo a Organização Mundial da Saúde - OMS (2006), o suicídio encontra-se vinculado às dez causas de morte que ocorrem com maior frequência. Entretanto, pressupõe-se que a quantidade de casos de morte por suicídio seja maior ainda, mesmo porque alguns casos não são devidamente notificados.

Visto que o número de casos de suicídios vem aumentando a cada dia que se passa de uma forma relevantemente rápida, principalmente em jovens, se faz necessário estudos aprofundados em prol deste tema, afim do entendimento de eventos que facilitam tal conduta para assim tornar-se possível a aplicação de medidas preventivas. Como a Psicologia lida com o indivíduo e os fenômenos subjacentes ao mesmo, assim como a morte, tal assunto faz-se relevante para essa ciência. O conhecimento sobre esse tema é extremamente importante, pois se torna uma ferramenta na qual os psicólogos necessitam ter acesso, para o manejo com pacientes que possuem comportamento suicida.

Mesmo tratando-se de um assunto demasiadamente grave, com consequências drásticas, ainda há muitas pessoas e profissionais que sabem pouco sobre como auxiliar alguém que apresente comportamentos comuns em uma ideação suicida há uma grande dificuldade até mesmo de identificar, perceber esse tipo de comportamento. O que se resulta disso é que as pessoas no geral e até mesmo os profissionais de saúde que por não possuírem instruções, conhecimento acerca dessa temática, acabam acreditando em mitos como: "quem fala em suicídio raramente o faz, ou até mesmo perguntar sobre suicídio pode desencadear o suicídio" (OMS, 2000).

Os profissionais da saúde lidam constantemente com pacientes com ideação suicida, comportamento suicida, indivíduos que cogitaram alguma vez em suas vidas, tentar o ato de auto-extermínio, consequentemente estão em uma posição privilegiada para identificar possíveis sinais de alerta. Nesse sentido, está claro que precisam ser capazes de identificar fatores de risco, de proteção, é necessário que se inteirem do assunto e que estejam aptos para realizarem intervenções assertivas, sendo de fato, a proposta desse estudo.

\subsection{CONSIDERAÇÕES SOBRE O SUICÍDIO}

Tal ação, geralmente é caracterizada pela vontade do indivíduo de livrar-se da frustração que se faz necessário lidar, geralmente não pensa na morte especificamente e sim em uma forma de se esquivar do que têm lhe feito mau. Para Costa e Forteski (2013 p.50), a pessoa que tenta o suicídio, muitas vezes, não busca a morte como o desaparecimento real do mundo, o suicídio é mais uma tentativa de resolver conflitos e sofrimentos nos quais a existência se encontra, de libertar-se de 
uma ausência intolerável, a morte é apenas uma consequência.

\section{Para Durkheim (1897/2008) existem} quatro tipos de suicídio: egoísta, altruísta, anômico e fatalista. O suicídio egoísta trata-se da ausência da sociedade na vida do indivíduo, a solidão do mesmo, levando ao individualismo. Já o tipo altruísta, há a presença da sociedade em peso na vida do sujeito, e tal ato é executado por reflexos de comunitarismo em excesso. Há o tipo anômico, onde a ausência da sociedade é relacionada a crises, que acabam provocando o suicídio e por fim o tipo fatalista, no qual o indivíduo sente-se oprimido pelas pessoas que o cercam e busca fugir dessa pressão.

Silva et al. (2015), ressaltam a existência de preconceito e até mesmo vergonha, por parte de familiares de indivíduos suicidas, no que se refere a assumir a verdadeira causa da morte. Provocando certa dificuldade ao se mensurar os dados reais de suicídio consumado, muitas vezes os registros de suicídio não condizem com o que realmente ocorre, o verdadeiro motivo da morte pode ser mascarado.

O índice de mortalidade por suicídio pode ser ainda mais elevado do que os dados existentes, considerando-se que ocorrem diversas vezes subnotificações. Pelo fato de que ainda costuma-se tratar o suicídio como algo que não deve ser divulgado, para não influenciar assim a ocorrência de mais casos e também por ser percebido muitas vezes como um tabu, digno de vergonha. Nesse sentido, muitos casos são ocultados. Subentende-se que as estatísticas sobre o suicídio são ainda mais alarmantes (MACHADO; SANTOS, 2015).
Em relação à analogia entre suicídio e os meios de comunicação, pode-se observar que as informações primordiais de dados de indivíduos que se suicidaram logo depois da divulgação de suicídio, surgiram após a exposição da novela "Goethe Die Leiden des Jungen Werther" (Os Sofrimentos do Jovem Werther), publicada em 1774. O personagem da novela, o herói, se suicida por meio de um tiro, pelo fato de não possuir capacidades adaptativas para superar uma decepção amorosa. Após a distribuição do livro na Europa, muitos jovens cometeram suicídio da mesma forma, o que contribuiu para a proibição do livro e desencadeou o termo "Efeito Werther", no qual se referia a ao ato de reproduzir suicídios, assim como foram realizados (OMS, 2000).

É daí que se originou o receio da divulgação de casos de suicídio. Mídias como televisão, novelas, filmes, meios de comunicação em geral que abordem o suicídio são percebidos como meios de influência para que outras pessoas também cogitem a possibilidade de suicidar-se ou até mesmo de reproduzirem do modo que viram. Há a concepção de que pode também encorajar, ser exemplo para quem já reflete acerca de colocar um fim a vida.

\subsection{PSICOTERAPIA E SUICÍDIO}

De acordo com Avanci, Pedrão e Júnior (2005), foi verificado que entre os jovens que tentaram pôr um fim a própria vida, $10 \%$ conseguiram atingindo o suicídio consumado dentro de cerca de dez anos em seguida da primeira tentativa e que apenas $25 \%$ dos que tentaram, buscaram ajuda médica. 
Nesse sentido, estudos mostram que profissionais de saúde mental sentem-se mais mobilizados e possuem atitude mais positiva para com os pacientes que tentam suicídio do que aqueles que não atuam na área (KISHI et al, 2011, apud FREITAS; BORGES, 2014). Por isso é importante a procura de ajuda do profissional adequado, apto para tal, afim de que seja viável a forma de tratamento específica para cada caso, a psicoterapia é um método para lidar com pacientes com risco de suicídio.

Assim, momento em que o paciente procura a terapia, principalmente se for a primeira vez que busca o tratamento psicológico, o mesmo investe suas expectativas no terapeuta, coloca a esperança toda nele e não percebe que só vai conseguir chegar a algum lugar se houver mudança primeiramente nele mesmo. No entanto o que ocorre com frequência é o contrário, pacientes acreditando que a responsabilidade é somente do terapeuta (BECHELLI; SANTOS, 2005).

Ao deparar-se com um paciente com comportamento suicida, primeiramente, em relação a conduta do profissional, é preciso que o mesmo auxilie o indivíduo afim de que ele sintase em segurança, onde quer que se encontre. Para intervenções psicoterápicas em situações de crise, o terapeuta precisa conhecer profundamente as teorias que embasam esse tipo de psicoterapia e possuir alguns traços tais como: saber compreender o paciente, agir com naturalidade, tranquilidade, transmitir confiança. Mesmo porque, o indivíduo já chega com o estado emocional extremamente abalado, o mesmo precisa de um profissional que esteja de fato preparado para atendê-lo (Amorim, 2015).

Nesse sentido, além da relação entre a psicoterapia e o suicídio, é relevante saber também quais os métodos suicídio que são mais utilizados, pelo fato de auxiliar até mesmo em medidas preventivas relacionadas ao fenômeno. É necessária a consciência dessas informações afim de que o próprio terapeuta saiba orientar a família de seu paciente, para que os familiares se atentem até mesmo a objetos que devem ser retirados de perto de um indivíduo com comportamento suicida. São informações importantes não só para o terapeuta e para os familiares, mas para a sociedade em geral, segue um breve apanhado de trabalhos relacionados aos transtornos e comorbidades relacionados ao suicídio.

\subsection{TRANSTORNOS E COMORBIDADES RELACIONADAS AO SUICÍDIO}

Em conformidade com informações da OMS (2006), há uma prevalência maior, cerca de 10 vezes mais suicídios onde os indivíduos foram diagnosticados com alguma desordem relacionada a personalidade, em oposição a aqueles que não foram diagnosticados pertencentes a algum quadro de transtorno relacionado ao comportamento, a personalidade ou até mesmo com presença de indicativos de violência e agressão.

Para Barbosa et. al (2011), a concepção de comorbidade consiste em patologias individualizadas ocorrendo ao mesmo tempo em um paciente específico. A presença de ambas no mesmo espaço temporal modifica a forma em que a patologia irá se manifestar, o feedback ao 
tratamento submetido e até mesmo o prognóstico da doença. Estando a depressão como a principal psicopatologia relacionada ao suicídio, na literatura também há informações acerca de outros transtornos associados a tal fenômeno, assim como se fala muito a respeito de transtornos comórbidos, onde a correlação de ambos juntos intensifica o quadro psicopatológico do paciente.

Em conformidade com os estudos de Scussel et al. (2016), está claro que o Transtorno Bipolar tem sido bastante presente em indivíduos que tentam suicídio. Torna-se complexo um diagnóstico da doença por parte de um profissional, em decorrência desse transtorno aflorar-se e dar indícios somente no início da fase adulta. Tal transtorno muitas vezes está ligado a tentativas, ideação e suicídio consumado.

De acordo com Fernandes e Scippa (2013), nos casos de suicídio é bastante comum que haja transtornos de humor associados, cita como exemplo o Transtorno Afetivo Bipolar principalmente se houver comorbidade desse transtorno com transtornos de personalidade boderline, narcisista e antissocial. A respeito de pacientes com personalidade borderline e antissocial, Mazer, Macedo e Juruena (2017) percebe-se que o risco de suicídio é ainda maior se houver outras psicopatologias correlatas como a depressão. Ressaltam que o suicídio aparece como o principal motivo de morte em indivíduos com transtorno de personalidade, principalmente os que possuem o transtorno de personalidade borderline.
Dados dos estudos de Vasconselos, Lôbo e Neto (2015) abrangendo o Transtorno de Ansiedade Generalizada - TAG demonstram que tal transtorno por si só pode aumentar o risco de suicídio, porém, pacientes com depressão e TAG correlato, denotam mais probabilidade de tentativas de suicídio do que aqueles que não possuem tal comborbidade. Seja ocorrendo antes ou ao mesmo tempo a realidade é que o TAG agrava o comportamento suicida em indivíduos depressivos.

Conforme Amorim (2015), da quantidade existente de suicídios, os principais transtornos que permeiam o comportamento suicida são os transtornos de humor, transtornos associados á dependência química, os de personalidade e por fim esquizofrenia. Ressalta a depressão correlata a algum outro transtorno e o uso excessivo de drogas psicoativas. Lins, Oliveira e Coutinho (2006), seguem a mesma linha de raciocínio em relação a exacerbação dos transtornos psicológicos quando há comorbidade, abrange os transtornos que já foram trazidos por meio deste trabalho, falando acerca também da esquizofrenia, onde em torno de $10 \%$ a $15 \%$ dos pacientes suicidam-se mediante o progresso do transtorno.

Mesmo que a explanação acima seja breve, é possível perceber como os transtornos e comorbidades estão presentes no comportamento suicida e no suicídio consumado. Em função disso, se faz tão importante um diagnóstico bemfeito e intervenções assertivas. É primordial uma consciência maior em relação a isso, já que é um fator de risco tão relevante, é preciso que os profissionais e a sociedade o compreendam o 
quão grave é. E também o quanto os sinais de alerta, principalmente quando há um diagnóstico, devem ser observados, acompanhados e o transtorno deve ser tratado e bem tratado.

A hipótese do presente trabalho foi a de que psicopatologias são os fatores de risco mais influentes no comportamento suicida. Neste segmento, o objeto de investigação deste trabalho possui o seguinte problema como questionamento: Quais são os fatores subjacentes às tentativas de suicídio existentes na literatura e quais as intervenções psicoterápicas mais utilizadas? Perante essa questão o estudo objetiva realizar uma revisão de bibliografia a respeito do suicídio e os fatores que o permeiam, em artigos de periódicos nacionais e internacionais no período de 2000 a 2017. E de maneira específica verificar se os sujeitos apresentam algum tipo de transtorno associado às tentativas de suicídio; identificar a presença de fatores de risco; analisar as formas de intervenções psicoterápicas mais utilizadas e fornecer subsídios compilados que possam auxiliar os profissionais na realização de intervenções mais assertivas.

\section{MATERIAL E MÉTODO}

O presente estudo constitui-se em uma pesquisa de delineamento bibliográfico visando uma análise de obras da literatura pertinente. Considerando a relevância do tema e assim buscando conhecer a perspectiva de alguns autores a respeito do suicídio, fatores que $o$ permeiam e também a articulação da psicoterapia em relação ao fenômeno em estudo, fez-se o uso dos pressupostos da revisão integrativa da literatura. O que tornou possível o conhecimento de artigos produzidos sobre o tema deste trabalho, abrangendo também as tentativas e ideação suicida, mesmo porque a relação entre tais momentos é diminuta.

No que se refere à revisão integrativa da literatura, de fato, tal método de pesquisa possibilita a análise de estudos realizados anteriormente, de modo que seja possível auxiliar na prática clínica, trazendo conhecimentos pertinentes acerca da temática estabelecida, fornecendo embasamento para decisões mais assertivas por parte dos profissionais (MENDES; SILVEIRA; GALVÃO, 2008).

Nesse seguimento, para o desenvolvimento do estudo e melhor conhecimento acerca de tal temática, este estudo foi elaborado por meio dos registros, análise e organização dos dados bibliográficos, instrumentos que permitem uma maior compreensão do assunto, possibilitando uma interpretação crítica das fontes obtidas. Para tal foram usados os seguintes critérios de inclusão: a) estudos produzidos no período de publicação de 2000 a 2017; b) publicações em português e inglês.

Inicialmente foi executada a leitura dos títulos dos artigos, encontrados por meio das palavras-chave, em seguida os resumos dos artigos nos quais os títulos correspondiam aos objetivos da pesquisa foram lidos, para que fosse possível selecionar apenas aqueles relacionados a esta área de conhecimento. Posteriormente, os artigos foram lidos na íntegra e selecionados os que concernem à pesquisa. Logo depois ocorreu a análise e inclusão de alguns artigos de outros estudos, localizados nas referências dos artigos selecionados, capazes 
de corresponder aos critérios de inclusão estabelecidos.

Foi realizado um recorte temporal no período de publicação entre 2000 a 2017 onde foram incluídos artigos indexados nas seguintes bases de dados: Biblioteca Virtual de Psicologia Bvs-Psi, Scientific Electronic Library Online Scielo, LILACS (Literatura Latino-Americana e do Caribe em Ciências da Saúde), e Portal de Periódicos Eletrônicos de Psicologia (PePSIC). Foram utilizadas as seguintes palavras-chaves: suicídio, psicoterapia, depressão, suicide.

FIGURA 1 - Seleção dos artigos nas bases de dados: Bvs-Psi, Scielo, LILACS e PePSIC.

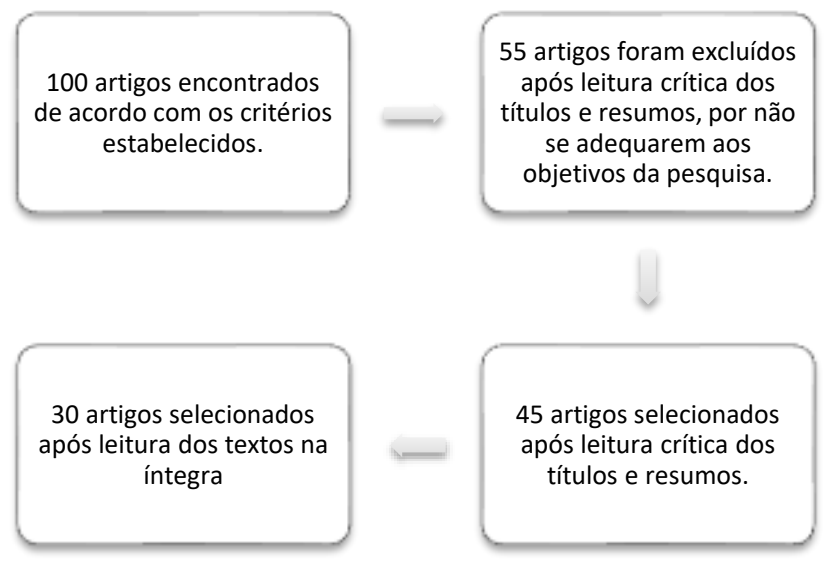

\section{RESULTADOS E DISCUSSÃO}

A seguir encontram-se os resultados da presente pesquisa, segue abaixo os artigos utilizados, representados por meio de um quadro. Estão dispostos os títulos e autores referentes aos 30 artigos que contribuíram para a análise dos dados deste trabalho.
QUADRO 1 - Títulos dos artigos e autores utilizados para análise dos dados

\begin{tabular}{|l|l|l|}
\hline $\begin{array}{c}\mathbf{N}^{\circ} \\
\text { artigo }\end{array}$ & \multicolumn{1}{|c|}{ TítULO } & \multicolumn{1}{c|}{ AUTORES } \\
\hline $\mathbf{0 1}$ & $\begin{array}{l}\text { Terapia cognitivo- } \\
\text { comportamental no manejo } \\
\text { da desesperança } \quad \text { C. (2014) }\end{array}$ & Marback R. e Pelisoli \\
& $\begin{array}{l}\text { pensamentos suicidas. } \\
\end{array}$ &
\end{tabular}

02 Prevalência e fatores

Moreira L. e Bastos associados à ideação suicida na adolescência: revisão de literatura.

03 Risco de suicídio em paciente alcoolista com depressão.

04 Acompanhamento terapêutico: intervenção sobre a depressão e o suicídio.

P. (2015)

King A., Nardi A. e Cruz M. (2006)

Lins C., Oliveira V. e Coutinho M. (2006)

05 Comportamento suicida entre dependentes químicos

06 Revisão: comportamento suicida ao longo do ciclo vital.

07 Tentativa de suicídio: reflexões em base a clínica centrada na pessoa.

08 Atendimento de pacientes com comportamento suicida na prática médica

Quais são os recentes achados clínicos sobre a associação entre depressão e suicídio?

Cantão L. e Botti N. (2015)

Schlösser A., Rosa G., More C. (2014)

Fonseca E., Lôbo W., (2015)

Meleiro A. (2013)

Chachamovich E., Stefanello S. Botega N. e Tureck G. (2009)

10 Níveis de ideação suicida em jovens adultos

Raposo J., Soares A., Silva F., Fernandes M. e Teixeira C. (2016)

11 Comportamento suicida no transtorno afetivo bipolar e características

sociodemográficas, clínicas e neuroanatômicas associadas

12 Retratos de autópsias Psicossociais sobre suicídio de idosos em Teresina
Fernandes F., Scippa A. (2012)

Sérvio S. e Cavalcante A. (2013) 


\section{Continuação da Tabela}

\begin{tabular}{|c|c|c|}
\hline $\begin{array}{l}\mathrm{N}^{\circ} \\
\text { artigo }\end{array}$ & TÍTULO & AUTORES \\
\hline 13 & \begin{tabular}{l}
\multicolumn{3}{l}{ Determinantes espaciais e } \\
socioeconômicos do \\
suicídio no Brasil: uma \\
abordagem regional
\end{tabular} & $\begin{array}{l}\text { Gonçalves L., } \\
\text { Gonçalves } \quad \text { E. } \\
\text { Júnior L. (2011) }\end{array}$ \\
\hline 14 & $\begin{array}{l}\text { Violência } \\
\text { transtornos de humor e } \\
\text { risco de suicídio: um } \\
\text { estudo de base } \\
\text { populacional }\end{array}$ & $\begin{array}{l}\text { Mondin T. et. al } \\
(2016)\end{array}$ \\
\hline 15 & $\begin{array}{l}\text { Risco de suicídio e } \\
\text { comorbidades psiquiátricas } \\
\text { no transtorno de ansiedade } \\
\text { generalizada }\end{array}$ & $\begin{array}{l}\text { Vasconselos J. } \\
\text { Lôbo A., Neto } \\
\text { V. (2015) }\end{array}$ \\
\hline 16 & $\begin{array}{l}\text { Suicide risk in } \\
\text { addicts with a cocaine } \\
\text { depressive } \\
\text { episode: feelings } \\
\text { experiences. }\end{array}$ & $\begin{array}{l}\text { Rocha C. et al } \\
(2015)\end{array}$ \\
\hline 17 & $\begin{array}{l}\text { Tentativas e suicídios por } \\
\text { intoxicação exógena no } \\
\text { Rio de Janeiro, Brasil: } \\
\text { análise das informações } \\
\text { através do linkage } \\
\text { probabilístico }\end{array}$ & $\begin{array}{l}\text { Santos } \\
(2014)\end{array}$ \\
\hline 18 & $\begin{array}{l}\text { Prevalência e fatores } \\
\text { associados à ideação } \\
\text { suicida na adolescência: } \\
\text { revisão de literatura. }\end{array}$ & 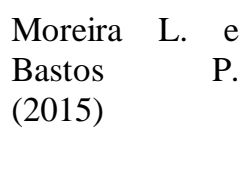 \\
\hline 19 & $\begin{array}{l}\text { Risco de suicídio em } \\
\text { paciente alcoolista com } \\
\text { depressão. }\end{array}$ & $\begin{array}{l}\text { King A., Nardi } \\
\text { A. e Cruz M. } \\
(2006)\end{array}$ \\
\hline 20 & $\begin{array}{llr}\text { Pacientes em Risco de } \\
\text { Suicídio: Avaliação da } \\
\text { Ideação Suicida e o } \\
\text { Atendimento Psicológico. }\end{array}$ & $\begin{array}{ll}\text { Ferreira } & \text { C. } \quad \& \\
\text { Gabarra } & \text { L. } \\
(2014) & \end{array}$ \\
\hline 21 & $\begin{array}{l}\text { Estudo qualitativo sobre } \\
\text { tentativas e ideações } \\
\text { suicidas com } 60 \text { pessoas } \\
\text { idosas brasileiras. }\end{array}$ & $\begin{array}{l}\text { Cavalcante } \\
\text { Minayo e } \\
(2015)\end{array}$ \\
\hline 22 & $\begin{array}{l}\text { Suicídio em cidades } \\
\text { históricas de um estado } \\
\text { brasileiro. }\end{array}$ & $\begin{array}{l}\text { Simões } \\
\text { Cantão L., } \\
\text { Botti N. }(2015)\end{array}$ \\
\hline 23 & $\begin{array}{l}\text { Tentativas e suicídios por } \\
\text { intoxicação exógena no } \\
\text { Rio de Janeiro, Brasil: } \\
\text { análise das informações } \\
\text { através } \\
\text { do linkage probabilístico }\end{array}$ & $\begin{array}{l}\text { Santos et. al } \\
(2014)\end{array}$ \\
\hline
\end{tabular}

\section{Continuação da Tabela}

\begin{tabular}{|c|c|c|}
\hline $\mathbf{N}^{\circ}$ artigo & TÍTULO & AUTORES \\
\hline 24 & $\begin{array}{l}\text { Histórico de Violência } \\
\text { Intrafamiliar em } \\
\text { Pacientes Psiquiátricos }\end{array}$ & $\begin{array}{l}\text { Padovani R., } \\
\text { Williams L. (2008) }\end{array}$ \\
\hline 25 & $\begin{array}{l}\text { Distorções do } \\
\text { pensamento em } \\
\text { pacientes deprimidos: } \\
\text { frequência e tipos }\end{array}$ & $\begin{array}{lc}\text { Medeiros } & \text { H. } \\
\text { Sougey E. (2010) }\end{array}$ \\
\hline 26 & $\begin{array}{lr}\text { Caso } & \text { Vera: } \\
\text { intervenções } & \text { do } \\
\text { psicoterapeuta } & \text { e } \\
\text { aliança terapêutica } & \end{array}$ & Peixoto et. al (2016) \\
\hline 27 & $\begin{array}{l}\begin{array}{l}\text { Fatores de } \\
\text { relacionados risco } \\
\text { suicídios em }\end{array} \\
\text { com } \\
\text { (TO), Brasil, 2006- } \\
\text { 2009, investigados por } \\
\text { meio de autópsia } \\
\text { psicossocial }\end{array}$ & $\begin{array}{l}\text { Ferreira N., Pessoa } \\
\text { V., Barros R., } \\
\text { Figueiredo A. e } \\
\text { Minayo M. (2014) }\end{array}$ \\
\hline 28 & $\begin{array}{l}\text { Substâncias tóxicas e } \\
\text { tentativas e suicídios: } \\
\text { considerações } \\
\text { acesso e sobre } \\
\text { restritivas. }\end{array}$ & $\begin{array}{l}\text { Santos S., Legay L. e } \\
\text { Lovisi G. (2013) }\end{array}$ \\
\hline 29 & $\begin{array}{l}\text { Estudo epidemiológico } \\
\text { da mortalidade por } \\
\text { suicídio no Estado do } \\
\text { Ceará, no período } \\
\text { 1997-2007. }\end{array}$ & $\begin{array}{l}\text { Oliveira M., Filho J.e } \\
\text { Feitosa F. (2012) }\end{array}$ \\
\hline 30 & $\begin{array}{l}\text { Suicídio no Brasil, de } \\
2000 \text { a } 2012\end{array}$ & $\begin{array}{l}\text { Machado D. e Santos } \\
\text { D. (2012). }\end{array}$ \\
\hline
\end{tabular}

Fonte: Construção das autoras.

\subsection{FATORES ASSOCIADOS ÀS TENTATIVAS DE SUICÍDIO}

Há uma complexidade em relação aos fatores determinantes, pois muitas vezes são baseados em evidências proporcionadas por relatos de familiares, amigos, documentos. Contudo ao analisar a literatura pertinente podem-se destacar alguns dos quais são reincidentes em uma gama de casos. Na maioria das vezes, pode-se identificar a existência de alguma Psicopatologia, assim como é 
retratado por Botega, Werlang, Cais e Macedo (2006), onde os autores ressaltam que em 93-95\% dos casos há um diagnóstico psicopatológico, onde divide-se em transtornos de humor, com prevalência maior de depressão grave correspondendo a 40-50\% dos casos, dependência de álcool, (em torno de $20 \%$ dos casos) e esquizofrenia ( $10 \%$ dos casos).

A associação entre depressão e suicídio é extremamente congruente, tal psicopatologia consiste no principal fator associado ao comportamento suicida, segundo a literatura. Trata-se do transtorno que mais têm tido prevalência permeando as tentativas de suicídio, uma série de estudos mostram que o risco de suicídio aumenta mais de 20 vezes em indivíduos com episódio depressivo maior e é ainda maior em casos em que haja um transtorno psiquiátrico juntamente com a depressão (CHACHAMOVICH et al. 2009).

Além da depressão, o transtorno bipolar também tem se mostrado prevalente nas tentativas de suicídio. Dados da literatura acerca deste predomínio podem estar relacionados a demora para se chegar a um diagnóstico, que pode acarretar em maior gravidade do transtorno, além da polifarmácia, o uso de uma série de medicamentos em um mesmo paciente ou até mesmo a comorbidade com outro transtorno de ordem psicológica (FERNANDES; SCIPPA, 2012).

O transtorno de personalidade borderline provoca uma excessiva dificuldade afetiva e também leva a impulsividade, predisposição a agressão ao próprio corpo e tendem a ter comportamento suicida, principalmente quando é comórbido a outras psicopatologias como transtorno de humor, verifica-se uma exacerbação dos riscos de suicídio. Acerca da relação entre transtorno de personalidade borderline e suicídio os estudos de Pastore e Lisboa (2015), corroboram com achados na literatura existente.

Outro fator bastante associado às tentativas de suicídio trata-se do uso de substâncias psicoativas, na literatura pertinente a essa linha de pesquisa, foram encontrados diversos artigos nos quaispode se observar uma relação forte entre o comportamento suicida e esse fator. Segundo Lovisi et al. (2009), um dos principais aspectos relacionados ao suicídio é o abuso/dependência de álcool e drogas. A isso se acresce o fato de que quando há a presença de transtorno depressivo, o risco de intento de suicídio é potencializado.

Nesse seguimento, Moreira e Bastos (2015), ressaltam que a prevenção ao uso de álcool e drogas pode reduzir a tentativa de suicídio, principalmente em adolescentes. Sob outra perspectiva, Medeiros e Sougey (2010) mencionam o alcoolismo como um fator desencadeante de tentativas de suicídio. E deste modo ressalta que deve ser dada uma relevância maior a tal fator, visto que a prevalência do uso de álcool em pacientes suicidas mostra-se alta.

\section{Cantão e Botti (2016) abordam o} comportamento suicida em dependentes químicos, abrangendo drogas lícitas e ilícitas, os resultados das pesquisas dos mesmos corroboram o que foi trazido pelos outros autores. Ressaltam a prevalência alta de suicídio em dependentes químicos e o quão é importante avaliar o risco de suicídio ao lidar com um paciente com dependência de substâncias psicoativas. É um fator 
que exige atenção no manejo com tais pacientes.

Aos fatores de risco se acresce o sentimento de desesperança, no qual aparece altamente relacionado ao comportamento suicida com frequência na literatura. A desesperança constitui-se em uma perspectiva totalmente negativa sobre o que está por vir, há uma considerável falta de expectativas em relação ao futuro (PERGHER; STEIN; WAINER, 2004). O indivíduo perde o que o incentiva a viver, acredita que nada vai melhorar e que não possui motivos para estar vivo, chega ao ponto de não conseguir suportar sua própria vida acreditando piamente que essa situação extremamente negativa que se encontra não vai mudar, com isso percebe o suicídio como a única saída (MARBACK; PELISOLI, 2014).

Outro fator trazido diversas vezes pela literatura consiste no desemprego, no sexo masculino, mais ainda do que no feminino. Isso se deve o fato do homem sentir-se responsável pelo sustento da família, provocando assim intensa perturbação naqueles indivíduos que encontram-se desempregados principalmente se for durante um longo período de tempo, ao ponto de acreditarem que não vão conseguir um trabalho, o que provoca uma pressão muito forte (RAPOSO et al., 2016).

\subsection{DADOS DEMOGRÁFICOS}

Informações demográficas a respeito do suicídio são úteis para identificar grupos que possam estar inseridos em maior probabilidade de risco de suicídio, mas não podem nortear a avaliação de casos específicos, determinar o risco individual, pois este é dado por relações de variáveis, entretanto é relevante o conhecimento de tais dados, tanto para a sociedade no geral, quanto para os profissionais terem o conhecimento acerca de padrões de dados inerentes ao suicídio.

A maior parte dos dados demográficos encontrados na literatura demonstram que a tentativa de suicídio é mais comum em mulheres, mas o índice de suicídio consumado é mais elevado em homens, a cada três homens que falecem por suicídio uma mulher morre pela mesma causa. Percebe-se que os homens possuem dificuldade para procurar e aceitar que precisam de ajuda, mesmo encontrando-se em uma série de problemas emocionais ou psicológicos não costumam abrir-se, pedir o auxílio de alguém. E também utilizam métodos mais agressivos, o que reduz as probabilidades de sobrevivência (FERREIRA; GABARRA, 2014).

No que tange o suicídio no sexo masculino, questões de ordem financeira podem ser mais complexas para os homens lidarem e consequentemente um fator estressante que também pode influenciar na conduta suicida. Visto que a cultura responsabiliza o homem em relação ao que se refere ao sustento da casa, quando há uma situação de crise financeira, o mesmo pode abalar-se extremamente, por carregar tal responsabilidade (SCHLÖSSER; ROSA, 2014).

Verifica-se um padrão relacionado às tentativas de suicídio, onde a maioria são homens, solteiros, que não possuem filhos, de idade entre 15 á 44 anos e 65 anos na terceira idade. Nos idosos além da possibilidade do suicídio estar relacionado a algum transtorno psicológico ou psiquiátrico, a intencionalidade de suicídio pode ser influenciada também pela perda de atividade 
social, descobrimento de alguma doença, perda de parentes ou amigos próximos (SCHLOSSER; ROSA; MORE, 2014). Assim como também a morte de entes queridos, falta de afeto, de autonomia, condições financeiras desfavoráveis, violência ou uso de substâncias psicoativas e sofrimento em prol de doenças físicas incapacitantes e crônicas (CAVALCANTE; MINAYO, 2015).

Bem como nas outras faixas etárias, a preocupação com o suicídio na terceira idade é muito importante, visto que tal população cresce cada dia mais. A falta do convívio social, o fato de muitos dos idosos ficarem sozinhos, não possuírem alguém para conversar como ocorre em muitos casos, agregados a ausência de psicoterapia potencializam o risco para o suicídio. Viverem sozinhos também dificulta serem encontrados e ajudados.

Segundo Braga e Dell'Áglio (2013), o suicídio é um fenômeno bastante complexo, com diversas causas, é multideterminado, onde fatores biológicos, psicológicos,

sociais, sóciodemográficos e culturais que interatuam, um potencializando o outro. Nesse sentido as medidas preventivas devem abranger o indivíduo como um todo, permeando tais aspectos. Não é determinante que somente a pré-disposição genética resultará em intencionalidade de suicídio, porém quando há fatores biológicos interagindo com contextos complexos, com uma série de eventos aversivos, a probabilidade aumenta consideravelmente.

\subsection{SUICÍDIO, PSICOTERAPIA E FATORES DE PROTEÇÃO}

Em relação ao que concerne a Psicoterapia, Cerqueira e Lima (2015) salientam que o que pode ser prejudicial no manejo psicoterápico de pacientes com esse perfil e justamente na aproximação referida trata-se da dificuldade do profissional lidar com suas próprias emoções frente às emoções de seus pacientes. Sendo essas emoções muito intensas, depreciativas, o psicólogo pode não saber como agir ao se deparar com esses sentimentos, o que pode interferir na qualidade do tratamento. É justamente por isso que é extremamente necessário que o terapeuta tenha uma estrutura emocional bem definida, que ele possua capacidades adaptativas para lidar com um caso como esses que pode ser de uma complexidade muito grande. Ele precisa investir, se capacitar, estar preparado intelectualmente, emocionalmente para trabalhar com um paciente nesse estado.

A maioria dos dados acerca das intervenções psicoterápicas, independente de área de atuação ou abordagem ressaltam que o fator que mais se tem destacado é a importância da relação do terapeuta com o paciente. Também corroboram que o paciente considerar positiva a aliança terapêutica é um dos maiores preditores de resultados positivos ou não na psicoterapia. Se não há a presença de fatores como aceitação, confiança, gentileza, compreensão, calor e consideração humana, há grandes chances de que as intervenções psicoterápicas não tenham o efeito desejado.

Uma aliança terapêutica consistente auxilia no trabalho do terapeuta em prol da diminuição da desesperança e pensamentos 
suicidas, contribuindo para a melhora dos mesmos (Sudak, 2012, citado por Marback \& Pelisoli, 2014). Estudos realizados por Peixoto et al. (2016), corroboram com outros achados em relação a esse laço constituído entre o terapeuta e seu paciente, principalmente na fase inicial da terapia, onde o vínculo terapêutico é estabelecido, o que evidentemente irá impactar o decorrer do processo psicoterápico.

No que se refere a intervenções psicoterápicas em pacientes com comportamento suicida estudos mostram que a Terapia Cognitivo- Comportamental - TCC, tem se mostrado bastante eficaz no manejo com tais pacientes. Segundo Marback e Pelisoli (2014) em um estudo de Brown e colaboradores (2005) realizado em pacientes com altos níveis de desesperança, após 10 sessões de TCC, 50\% dos pacientes se tornaram menos propensos a tentar suicídio, diferindo-se do grupo que não foi submetido a intervenções. Notou-se que houve uma diminuição relevante no grau de elevação da desesperança, que é um fator muito presente quando se analisa um paciente com comportamento suicida.

Segundo Chachamovich et al. (2009), Em vários ensaios clínicos que buscaram avaliar intervenções psicossociais, que buscam diminuir a probabilidade de novas tentativas de suicídio, houve evidências de que contatos regulares com grupos de risco de suicídio chegaram a resultados eficazes, diminuindo o número de tentativas.

Afirma que a prática do psicólogo deve seguir as diretrizes do Código de Ética Profissional do Psicólogo, ser embasada nos preceitos éticos, manter o sigilo, porém se considerar pertinente a quebra de sigilo deve agir deste modo, mesmo porque é importante avisar a família se for identificado durante a sessão psicoterápica a possibilidade de tentativa de suicídio. Porém é um direito, não é obrigatório que o mesmo haja dessa forma (ZANA; KOVÁCS, 2013).

Em relação aos fatores protetivos que devem ser também levados em consideração no que tange a prática do psicólogo, os mais mencionados são em prol de uma relação familiar bem estabelecida onde o indivíduo possa procurar apoio quando necessitar, possuir filhos, como também a religiosidade e relações sociais bem estabelecidas. Além de outros aspectos relevantes que podem influenciar no que se refere ao risco de suicídio como: facilidade para solicitar ajuda quando necessário, autoconfiança, sentir-se bem e ser mais flexível em suas emoções (SCHLÖSSER et al., 2014).

Ter filhos e obter responsabilidades para com a família sentir-se bem com atividades diárias, assim como convívio social são fatores protetivos muito relevantes no que se refere às tentativas de suicídio. Percebe-se que principalmente na terceira idade, foi mostrado na literatura em diversos artigos que a maioria dos idosos que tenta suicídio não possui suporte familiar e social adequado, relações afetivas podem diminuir significativamente o risco de suicídio. Sérvio e Cavalcante (2013) abordam esses fatores de proteção e pondera o quanto as relações afetivas e a autonomia podem diminuir o risco de suicídio na terceira idade.

\subsection{SUBSÍdIOS PARA PROFISSIONAIS DE SAÚDE E PSICÓLOGOS}


Em concordância com os dados compilados, obtidos por meio deste trabalho, percebe-se que é extremamente importante que o psicólogo mantenha uma relação empática com seu paciente, tenha um vínculo bem estabelecido, para que deste modo o mesmo sinta-se à vontade para falar sobre o que exatamente tem prejudicado seu bem-estar e também a respeito do desejo de por um fim a própria vida. Principalmente quando o comportamento suicida se faz presente, é crucial que o paciente confie no psicólogo de maneira que o mesmo sinta que possa recorrer a qualquer momento que for necessário, como em uma situação de crise, afim de que haja a oportunidade do profissional intervir e manter uma relação satisfatória com o mesmo, como Cerqueira e Lima (2015) ressaltaram.

Ademais está claro que o profissional precisa ser capaz de lidar não somente com as emoções de seu paciente, isso vale também para as suas próprias emoções. Mesmo porque, o próprio não conseguirá consolidar um manejo psicoterápico adequado se não possuir controle de sua reação ao estar em um contexto psicoterápico que envolve todas as complexidades de ideação e comportamento suicida. Faz-se necessário que o psicólogo busque se capacitar em relação aos seus conhecimentos e técnicas, assim como também trabalhando suas próprias emoções. Considerando o fato de que as reações do paciente podem ser extremamente intensas, alarmantes, como foi mostrado neste trabalho, é necessário buscar o auto-aperfeiçoamento dia após dia, visto que o fenômeno está se enraizando de um modo cada vez mais preocupante.

Para os profissionais em geral e principalmente para os psicólogos, é imprescindível que os mesmos rompam com paradigmas como "quem fala em suicídio não vai concretizar o ato", percebe-se por meio dos dados levantados que essa crença é muito arraigada ainda a muitos profissionais da área da saúde, sendo a mesma extremamente errônea. $\mathrm{O}$ falar em suicídio pode indicar sinais de alguém que pede por ajuda, da mesma forma que há pessoas que não falam sobre o desejo de morrer, que possuem uma rigidez intensa sobre demonstrar o que tem passado, o que tem sofrido.

O psicólogo precisa focar-se nas entrelinhas de seu paciente, no que ele diz e até mesmo no que ele não diz, olhar e ouvir atentamente e profundamente o mesmo. É indispensável que o profissional disponha da perspectiva de que a subjetividade é algo muito intrínseco á cada indivíduo e a mesma pode variar ao extremo, de um para outro. $\mathrm{O}$ que pode parecer não serem motivos suficientes de pôr um fim a própria vida para um, pode causar impactos violentos em outro indivíduo. Cada pessoa possui suas vivências, seus motivos, suas necessidades, uma situação considerada simples, no momento errado torne-se algo grandioso.

Mesmo porque, pacientes suicidas já possuem uma conotação bastante negativa a respeito de suas vidas e isso contribui para o aumento do sentimento de tristeza, de não conseguir perceber saída alguma para uma série de conflitos em suas vidas, da desesperança, que foram fatores muito citados na literatura. Por 
isso, é preciso que os psicólogos se atentem a esses sinais, por menores que sejam, por mais que alguma situação pareça ser simples, é necessário olhar o paciente como um todo, percebendo até mesmo os aspectos mais subjacentes.

Ainda em relação aos paradigmas inassertivos, percebe-se que acreditar que falar sobre suicídio pode desencadear comportamento suicida e evitar o assunto com pacientes é uma concepção inverídica, porém muito arraigada ainda, como mostrado na literatura. Precisamos falar sim acerca do suicídio, dispor de mais políticas públicas, estudarmos sobre o fenômeno e dar a devida relevância, em prol de assim obtermos subsídios em prol de lutar conta o aumento do número de casos de suicídio consumado.

\section{CONSIDERAÇÕES FINAIS}

Em relação aos objetivos do estudo, os mesmos foram alcançados de maneira que foi possível verificar que os indivíduos que colocam um fim nas suas próprias vidas, na maioria dos casos possuem algum tipo de psicopatologia. Acerca dos fatores de risco há uma incidência maior no sexo masculino, de 15 a 44 anos, e na terceira idade, por volta dos 65 anos. Alguns dos mais citados são: abuso e dependência de substâncias psicoativas, depressão ou comorbidades associadas, doenças incapacitentes, desemprego, estar solteiro, não possuir filhos, não ter fatores protetivos a fim de distanciar o risco de suicídio.

Assim como foi mostrado na introdução deste estudo, realmente o índice de suicídio é alarmante, é preciso uma mobilização maior em prol de diminuir essa prevalência tão alta. É imprescindível que a sociedade, os profissionais de saúde percebam a complexidade desse fenômeno e não negligenciem tentativas de suicídio, por mais que os motivos que levam a esse ato pareçam não justificar tamanha manifestação agressiva contra a vida. Precisamos entender que cada um possui sua singularidade e reage da forma que consegue frente eventualidades aversivas. Faz-se necessário também que sejam realizados mais estudos em prol de intervenções psicoterápicas em pacientes com comportamento suicida.

\section{REFERÊNCIAS}

AMORIM C. Crise Suicida: Avaliação e manejo. Psicologia Argumento, 33(80), pp. 221-223, 2015. doi: 10.7213/psicol.argum.33.080.REO01

ANDRADE, C.; HOLANDA A. Apontamentos sobre pesquisa qualitativa e pesquisa empíricofenomenológica. Estudos de Psicologia, 27(2), 259268. 2010. doi: https://dx.doi.org/10.1590/S0103$\underline{166 \times 2010000200013}$

AVANCI, R.; PEDRÃO, L.; JUNIOR, M.. Perfil do adolescente que tenta suicídio em uma unidade de emergência. Revista Brasileira de Enfermagem, 58 (5), 535-539, 2005. doi: http://dx.doi.org/10.1590/S003471672005000500007.

BARBOSA I., et al.. Comorbidades clínicas e pisquiátricas em pacientes com transtorno bipolar do tipo I. Jornal Brasileiro de Psiquiatria, 60(4), 271276, 2011.

BECHELLI, L.; SANTOS, M. O terapeuta na psicoterapia de grupo. Revista Latino-Americana de Enfermagem, 13(2), 249-254, 2005. doi: https://dx.doi.org/10.1590/S0104$\underline{11692005000200018}$

BOAVA, D.; FELÍCIO, M. . Contribuições da fenomenologia para os estudos organizacionais. Cadernos EBAPE.BR, 9 (spe 1), pp. 469-487, 2011. 
doi: https://dx.doi.org/10.1590/S1679-

39512011000600003

BOTEGA, N.. Comportamento suicida: epidemiologia. Psicologia USP, 25(3), 231-236, 2014. Doi: https://dx.doi.org/10.1590/0103$\underline{6564 \mathrm{D} 20140004}$

BOTEGA, N. et al. Prevalência de ideação, plano e tentativa de suicídio: um inquérito de base populacional em Campinas, São Paulo, Brasil. Cadernos de Saúde Pública. 25 (12), 2632-2638, 2009. doi: https://dx.doi.org/10.1590/S0102$\underline{311 X 2009001200010}$

BRASIL. Estratégia nacional de prevenção do suicídio: Manual dirigido a profissionais das equipes de saúde mental. Brasília: Ministério da Saúde, 2006.

CANTÃO, L.; BOTTI, N.. Comportamento suicida entre dependentes químicos. Revista Brasileira de Enfermagem, 69(2), 389-396, 2016. Doi: https://dx.doi.org/10.1590/0034-7167.2016690224i

CAVALCANTE, F.; MINAYO, M. Estudo qualitativo sobre tentativas e ideações suicidas com 60 pessoas idosas brasileiras. Ciência \& Saúde

Coletiva, 20(6), 1655-1666, 2015. Doi:

https://dx.doi.org/10.1590/1413-

$\underline{81232015206.06462015}$

CERQUEIRA, Y.; LIMA, P. Suicídio: a prática do psicólogo e os principais fatores de risco e de proteção. Revista IGT na Rede, v. 12, n 23, p. 444 $-458,2015$.

CHACHAMOVICH, E. et al. Quais são os recentes achados clínicos sobre a associação entre depressão e suicídio? Revista Brasileira de

Psiquiatria, 31(Suppl. 1), S18-S25, 2009. Doi: https://dx.doi.org/10.1590/S1516$\underline{44462009000500004}$

COSTA, M.; FORTESKI, R. O constrangimento de ser e a alienação existencial como hipóteses Fenomenológico- Existenciais para o ato de suicidar-se. Psicopatologia Fenomenológica Comtemporânea, 2(1), 42-56, 2013.

COUTINHO, A. Suicídio e laço social. Reverso, 32, (59), 61-69, 2010.

DURKHEIM, E. O suicídio. São Paulo: Martin
Claret, 2008.

FERNANDES, F; SCIPPA, A. Comportamento suicida no transtorno afetivo bipolar e características sociodemográficas, clínicas e neuroanatômicas associadas. Archives of Clinical Psychiatry (São Paulo), 40(6), 220-224, 2013. Doi: https://dx.doi.org/10.1590/S0101$\underline{60832013000600003}$

FERREIRA C.; GABARRA L.. Pacientes em Risco de Suicídio: Avaliação da Ideação Suicida e o Atendimento Psicológico. Journal of Health Sciences UNOPAR Cient Ciênc Biol Saúde 2014;16 (2):113-22. http://dx.doi.org/10.17921/2447$\underline{8938.2014 v 16 n 2 p \% 25 p}$

FOTTI, S. A. et al... The associations between peer and parental relationshipsand suicidal behaviours in early adolescents. Canadian Journal of Psychiatry, 51, 698-703, 2006. Disponível em:

http://publications.cpaapc.org/browse/sections/0

FREITAS, A.; BORGES, L. Tentativas de suicídio e profissionais de saúde: significados possíveis. Estudos e Pesquisas em Psicologia, 14(2), 560-577, 2014. Disponível em:

http://pepsic.bvsalud.org/scielo.php?script=sci_arttex t\&pid=S1808-42812014000200010\&lng=pt\&tlng=pt.

GIL, A. C. Como elaborar projetos de pesquisa. Atlas, V. 4, São Paulo, 2007.

LINS, C. et al.. Prevenção, adesão, promoção de saúde e reabilitação sob o acompanhamento terapêutico. Psicologia, 26, (2), 41-66, 2012.

LOVISI, G. et al. Análise epidemiológica do suicídio no Brasil entre 1980 e 2006. Revista Brasileira de Psiquiatria, 31(Suppl. 2), 86-93, 2009. Doi: https://dx.doi.org/10.1590/S1516$\underline{44462009000600007}$

MACHADO, D.; SANTOS, D.. Suicídio no Brasil de 2000 a 2012. Jornal Brasileiro de

Psiquiatria, 64(1), 45-54, 2015.

Doi: $\underline{\text { https://dx.doi.org/10.1590/0047-2085000000056 }}$

MARBACK, R.; PELISOLI, C. Terapia cognitivocomportamental no manejo da desesperança e pensamentos suicidas. Revista Brasileira de Terapias Cognitivas, 10(2), 122-129, 2014. Doi: https://dx.doi.org/10.5935/1808-5687.20140018 
MARCONI, M.; LAKATOS, E. Técnicas de pesquisa: planejamento e execução de pesquisas, amostragens e técnicas de pesquisas, elaboração, análise e interpretação de dados. $6^{\text {a }}$ edição, São Paulo: Atlas, 2007.

MAZER, A.; MACEDO, B.; JURUENA, M. Transtornos da personalidade. Medicina (Ribeirão Preto, Online, 50(1), 85-97, 2017. Disponível em: http://dx.doi.org/10.11606/issn.21767262.v50isupl1.p85-97

MEDEIROS, H.; SOUGEY, E. Distorções do pensamento em pacientes deprimidos: frequência e tipos. Jornal Brasileiro de Psiquiatria, 59(1), 2833, 2010. Doi: https://dx.doi.org/10.1590/S0047$\underline{20852010000100005}$

MENDES, K.; SILVEIRA, R. ; GALVÃO, C. . Revisão integrativa: método de pesquisa para a incorporação de evidências na saúde e na enfermagem. Texto \&contexto - Enfermagem 17( 4 ), pp. 758-764, 2008. Doi:

http://dx.doi.org/10.1590/S0104$\underline{07072008000400018 .}$.

MIRANDA, C.; TARASCONI, C.; SCORTEGAGNA, S. Estudo epidêmico dos transtornos mentais. Avaliação Psicológica, 7, (2), 249-257, 2008.

\section{ORGANIZAÇÃO MUNDIAL DA SAÚDE.}

Prevenção do suicídio: um manual para profissinais da saúde. Genebra, 2000. Disponível em:

http://www.who.int/mental_health/prevention/suicid e/en/suicideprev_media_port.pdf.

\section{ORGANIZAÇÃO MUNDIAL DA SAÚDE.}

Prevenção do suicídio, um recurso para conselheiros. Genebra: Departamento de Saúde Mental e de Abuso de Substâncias, 2006. Disponível em:

www.who.int/mental_health/media/counsellors_port uguese.pdf. Acesso em: agosto 28, 2016.

\section{ORGANIZAÇÃO MUNDIAL DA SAÚDE.}

Prevenção do suicídio: um manual para profissinais da saúde. Genebra, 2000. Disponível em:

http://www.who.int/mental_health/prevention/suicid e/en/suicideprev_media_port.pdf.

\section{ORGANIZAÇÃO MUNDIAL DA SAÚDE.}

Prevenção do suicídio, um recurso para conselheiros. Genebra: Departamento de Saúde
Mental e de Abuso de Substâncias, 2006. Disponível em:

http://www.who.int/mental_health/media/counsellors portuguese.pdf Acesso em: fevereiro 4, 2013.

PASTORE, E.; LISBOA, C. Desempenho cognitivo em pacientes com Transtorno de Personalidade Borderline com e sem histórico de tentativas de suicídio. Psicologia Clínica, 27(2), 139-159, 2015. Disponível em:

http://pepsic.bvsalud.org/scielo.php?script=sci_arttex t\&pid=S0103-56652015000200008\&lng=pt\&tlng=pt.

PEIXOTO, E. et al. D.. Caso Vera: intervenções do psicoterapeuta e aliança terapêutica. Temas em

Psicologia, 24(4), 1205-1215, 2016. Doi:

https://dx.doi.org/10.9788/TP2016.4-02Pt

PERGHER, G.; STEIN, L.; WAINER, R..Estudos sobre a memória na depressão: achados e implicações para a terapia cognitiva. Archives of Clinical

Psychiatry (São Paulo), 31(2), 82-90, 2004. Doi: https://dx.doi.org/10.1590/S010160832004000200004

RAPOSO, J. et al.. Níveis de ideação suicida em jovens adultos. Estudos de Psicologia (Campinas), 33(2), 345-354, 2016.

Doi: https://dx.doi.org/10.1590/1982$\underline{02752016000200016}$

Santos S., Legay L., Lovisi G., Santos J. e Lima L. (2013) Suicídios e tentativas de suicídio por intoxicação exógena no Rio de Janeiro: análise dos dados dos sistemas oficiais de informação em saúde, 2006-2008. Revista Brasileira de Epidemiologia, 16(2), 376-387.

Santos S., Lovisi G., Legay L. e Abelha L. (2009). Prevalência de transtornos mentais nas tentativas de suicídio em um hospital de emergência no Rio de Janeiro, Brasil. Cad. de Saúde Pública, 25, (9), 20642074. doi: https://dx.doi.org/10.1590/S0102311X2009000900020

SCHLÖSSER, A.; ROSA, G.; MORE, C.. Revisão: comportamento suicida ao longo do ciclo vital.

Temas em Psicologia, 22(1), 133-145, 2014. Doi: https://dx.doi.org/10.9788/TP2014.1-11

SCUSSEL, F. et al.. Perfil clínico dos pacientes com transtorno bipolar atendidos em um ambulatório especializado na região sul catarinense. Arq. Catarin Med. out-dez; 45(4):03-10, 2016. Disponível em: 
http://www.acm.org.br/acm/seer/index.php/arquivos /article/view/133/109

SILVA, A. et al. Psicoterapia: um artigo de revisão integrativa de literatura, 1-5, 2010. Disponível em: revista.ulbrajp.edu.br/ojs/index.php/salao/article/vie w/2357/759

SOUZA, D.; ZIONI, F. Novas perspectivas de análise em investigações sobre o meio ambiente: a teoria das representações sociais e a técnica qualitativa da triangulação de dados. Saúde e Sociedade, 12(2), 76-85, 2013.

VASCONSELOS, J. LÔBO, A., NETO, V. Risco de suicídio e comorbidades psiquiátricas no transtorno de ansiedade generalizada. Jornal Brasileiro de Psiquiatria, 64(4), 259-265, 2015. Doi: https://dx.doi.org/10.1590/0047$\underline{2085000000087}$

VIDAL, C. ; GONTIJO, E.. Tentativas de suicídio e o acolhimento nos serviços de urgência: a percepção de quem tenta. Cad. Saúde Colet., 21 (2), 108-114, 2013.

VIEIRA, K.; SARAIVA, E.; COUTINHO, M. Entrelaçamento entre depressão e suicídio segundo futuros psicólogos. PSICO, 41(02), 176-183, 2010.

\section{Como citar este artigo (Formato ABNT):}

SILVA, Jéssica Vieira de Sousa; MOTTA, Hinayana Leão. Comportamento suicida: uma revisão integrativa da literatura. Educação, Psicologia e Interfaces, vol.1, n.2, p. 51-67, 2017. DOI: https://doi.org/10.37444/issn-2594$\underline{5343 . v 1 i 2.25}$

Recebido: 02/11/2017.

Aceito: 23/12/2017. 